DOI - 10.21707/gs.v10.n02a03

\title{
Crescimento de Chlorella Vulgaris (Chlorophyta unicelular) na Presença DE COMPOSTOS FENÓLICOS
}

\author{
Nunes da Silva A.S. ${ }^{1}$; Geraldes A.M. ${ }^{1}$; Aires A. ${ }^{2} \&$ Fernandes C. $^{1 *}$ \\ ${ }^{I} I P B / C I M O$ - Instituto Politécnico de Bragança - Centro de Investigação de Montanha, Campus de Santa Apolónia, Apartado 1038, 5301 -854 Bragança, Portugal \\ ${ }^{2}$ UTAD /CITAB - Universidade de Trás-os-Montes e Alto Douro - Centro de Investigação e Tecnologias Agroambientais e Biológicas, Apartado 1013, 5001-801 Vila Real, Portugal \\ "Corresponding author: E-mail: conceicao.fernandes@ipb.pt.Fax: +351 273325405.
}

Recebido em 15 de dezembro de 2015. Aceito em 18 de junho de 2016. Publicado em 09 de dezembro de 2016.

\begin{abstract}
Resumo - Neste trabalho avaliou-se o efeito de diferentes tipos de extractos da planta de rosmaninho (Rosmarinus officinalis) ricos em compostos fenólicos, no crescimento e na fisiologia da microalga Chlorella vulgaris. Os extractos foram obtidos por infusão aquosa a quente e a frio, esta ultima com dois períodos de extração (5 e 21 dias). Os ensaios foram desenvolvidos em culturas batch com extratos à concentração de 10\%, 25\% e 30\% (v/v).

Os resultados mostraram para os extractos a frio que o crescimento da microalga foi afetado apenas com extratos de 21 dias, levando ao aumento da taxa específica de crescimento ( $\mu$ ) e da densidade celular, bem como da concentração de clorofila a $(\mathrm{Chl}$ a) e do teor em proteinas, numa relação direta com a concentração de extrato testada. A exposição aos extractos a quente apesar de levar ao aumento de $\mu$ e da densidade celular final de C. vulgaris, concomitantemente induziu alguma toxicidade a nível fisiológico, visível pela diminuição dos teores de Chl a e proteínas.

Os compostos fenólicos identificados por HPLC, nestes dois tipos de extratos, mostraram diferenças qualitativas e quantitativas. O extrato a frio apresentou essencialmente ácido rosmarínico e quercetina, enquanto que no extrato a quente foram quantificados sete compostos distintos, sendo os mais abundantes os ácidos rosmarínico e gálico.

Considerando o perfil de compostos fenólicos encontrado, é possível concluir que o grau de inibição/estimulo do crescimento de C. vulgaris está relacionado com a concentração e composição em compostos fenólicos dos extractos estudados.
\end{abstract}

Palavras-chave: Chlorella vulgaris, Extractos de Rosmarinus officinalis, Compostos fenólicos, EstimulaÇ̃̃o/InibiÇ̃̃o do CRescimento em microalgas

\section{Growth of Chlorella vulgaris (Unicellular Chlorophyta) in THE PResence of Phenolic compounds}

Abstract - In the present research the effect of different types of plant extracts of rosemary (Rosmarinus officinalis) rich in phenolic compounds was evaluated on the growth and physiology of microalgae Chlorella vulgaris. The aqueous extracts were obtained by infusion in cold and hot extraction process, this last with two periods (5 and 21 days). The tests were conducted in batch cultures with the extracts concentration of 10\%, 25\% and 30\% (v / v).

Concerning the cold extracts, results showed that the growth of microalgae was affected only by 21 days extracts, leading to increased specific growth rate $(\mu)$ and cell density, as well as chlorophyll a (Chl a) and proteins concentrations, in a direct relationship with the concentration of extract tested. The exposure to hot extracts, despite an increase $\mu$ and final cell density of $\mathrm{C}$. vulgaris, concomitantly induced also some physiological ltoxicity, perceptible by a decrease of $\mathrm{Chl}$ a and proteins content.

Phenolic compounds identified by HPLC, in these two types of extracts, showed quantitative and qualitative differences. The rosemary cold extract is mainly composed by rosmarinic acid and quercetin, whereas in hot extract seven different compounds were quantified, the most abundant being the rosmarinic and gallic acids.

Regarding to the profile of phenolic compounds founded, it seemed that the degree of inhibition/stimulation of microalgae growth of C. vulgaris is related to the concentration and composition of phenolic compounds of the extracts studied.

Key Words: Chlorella vulgaris, Rosmarinus officinalis extracts, Phenolic compounds, Microalgal growth inhibition/stimulation.

\section{Crecimiento de Chlorella vulgaris (Chlorophyta unicelular) ante la presencia de compuestos fenólico}

Aвstract - El presente estudio evaluó el efecto de diferentes tipos de extractos de plantas de romero (Rosmarinus officinalis) ricos en compuestos fenólicos, sobre el crecimiento y fisiología de la microalga Chlorella vulgaris. Los extractos acuosos se obtuvieron mediante la infusión caliente y frío, esta última extracción con dos períodos (5 y 21 días). Los ensayos se realizaron en cultivos discontinuos con la concentración de extractos de 10\%, 25\% y 30\% (v / v). Los resultados para los extractos fríos mostraron que el crecimiento de las microalgas se vio afectado sólo para los extractos con 21 días, conducente a lo aumento de la tasa específica de crecimiento $(\mu)$ y de la densidad de las células, bien como la concentración de clorofila a (Chl a) y el contenido de proteínas, en una relación directa con la concentración de extracto de ensayo. La exposición a los extractos en caliente, si bien han conducido a un aumento de $\mu$ y de la densidad final de células de C. vulgaris, concomitantemente han indujo cierta toxicidad a nivel fisiológico, visible por una disminución de contenido en Chl a y proteínas.

Los compuestos fenólicos identificados por HPLC, en estos dos tipos de extractos, mostraron diferencias cuantitativas y cualitativas. El extracto en frío presentó esencialmente el ácido rosmarínico y la quercetina, mientras que el extracto en caliente presentó siete compuestos distintos, los más abundantes siendo el ácido rosmarínico y el ácido gálico.

Teniendo en cuenta el perfil de los compuestos fenólicos encontrado, es posible concluir que el grado de inhibición/estimulación del crecimiento de C. vulgaris está relacionado con la concentración y composición de compuestos fenólicos de los extractos estudiados.

Palavras-Chave: Chlorella vulgaris, Extractos de rosmarinus officinalis, Compuestos fenólicos, estimulación/inhibición del crecimiento de microalgas.

\section{INTRODUÇÃO}

Os compostos fenólicos abarcam um grupo heterogéneo de substâncias com diferentes efeitos biológicos. Estescompostos encontram-se no ambiente como resultado do metabolismo secundário das plantas (Whiting 2001), mas também podem ocorrer como poluentes de origem antropogénica (Michałovitz and Duda 2007). Embora os efeitos bactericidas e fungicidas dos compostos fenólicos se encontrem amplamente documentados (Rauha et al 2000; Hafidh, et al 2011; Boulogne et al 2012; Zabka and Pavela 2013), os efeitos dos compostos fenólicos em microlagas são mais escassos (Nakai et al 2001; Laue et al 2014; 
Miazek et al 2014). Apesar disso, os fenómenos de lixiviação ou a deposição directa de efluentes, levam a que o reservatório final da maioria dos poluentes seja o ecossistema aquático.

Fernandes et al (2014) ao avaliarem o efeito de extractos de diversas plantas, ricos em compostos fenólicos, no crescimento de Chlorella vulgaris, verificaram que em função da concentração testada ocorria inibição ou estímulo do crescimento desta microalga. Outros autores (Megharaj et al. 1992; Al-Khalid and El-Naas, 2012) observaram diminuição da toxicidade associada a compostos fenólicos e até o estímulo do crescimento de C. vulgaris, em culturas sob condições fotoheterotróficas. De acordo com Lika and Papadakis (2009) e com Miazek et al (2014), a variação da toxicidade dos compostos fenólicos nas microalgas parece depender da sua concentração, das condições das culturas e das características dos compostos fenólicos.

De um modo geral, os compostos naturais comparativamente aos compostos de sítese, podem apresentar maior diversidade estrutural. Por outro lado, a investigação com extratos ricos em compostos fenólicos, comparativamente a compostos fenólicos purificados, poderá mostrar eventuais efeitos sinérgicos que ocorram, conduzindo, por isso, a avaliações mais realistas.

Assim, neste trabalho pretendeu-se avaliar os efeitos de diferentes concentrações de extractos de plantas ricos em compostos fenólicos no crescimento de Chlorella vulgaris, bem como avaliar a resposta fisiologica desta microalga, através da variação dos teores de clorofila $a$ e proteína total. Com base nos resultados de Fernandes et al 2014 e na ampla disponibilidade da planta na região, o alecrim (Rosmarinus officinalis) foi a planta selecionada, para a obtenção dos extratos.

\section{Material e métodos}

\section{Microalga Utilizada}

Foram utilizadas culturas monoalgais de Chlorella vulgaris (CBS15-2075), rotineiramente desenvolvidas em meio de Walne Modificado, agitadas continuamente por fluxo de ar, utilizando filtros autoclaváveis de $0.2 \mu \mathrm{m}$ e diâmetro de $50 \mathrm{~mm}$ (Millex ${ }^{\mathrm{TM}}$ ). As culturas foram mantidas a uma temperatura controlada de $25^{\circ} \mathrm{C}$, com iluminação de $4500 \mathrm{~lx}$ e com fotoperíodo de $16 \mathrm{~h} / 8 \mathrm{~h}$ luz/escuro. Os ensaios foram realizados assim que as culturas iniciavam a fase exponencial, avaliada por contagem do número de células em câmara de Neubauer.

\section{Preparação dos Extratos}

Amostragem do alecrim

O alecrim (Rosmarinus officinalis) foi colhido em Abril de 2012, na região de Trás-os-Montes, Portugal (41²77'48.72”N, 6046'1.97”W). Foram recolhidas flores, folhas e caules e posteriormente secos à temperatura ambiente, em envelopes de papel, no escuro, até serem utilizados. Para a obtenção dos extratos as flores, folhas e caules foram cortadas em pequenos bocados.

Obtenção dos extratos

Para a obtenção dos extratos aquosos a frio preparouse uma infusão de alecrim a $12 \%(\mathrm{~m} / \mathrm{v})$ em água destilada. A infusão foi feita em recipiente de plástico de $5 \mathrm{~L}$, conservado no escuro à temperatura ambiente e agitado diariamente. Foram testados extratos ao $5^{\circ}$ e $21^{\circ}$ dias. Para os ensaios, o extrato foi filtrado previamente por crivo de $45 \mu \mathrm{m}$ e levado aos UV durante 20 minutos.

Para a obtenção dos extratos aquosos a quente, num matraz preparou-se idêntica infusão de alecrim $(12 \% \mathrm{~m} / \mathrm{v})$, iniciando-se de seguida o seu aquecimento $\left(70^{\circ} \mathrm{C} / 3 \mathrm{~h}\right)$. A amostra foi tapada com vidro de relógio para evitar evaporação. Após, o extrato foi filtrado por crivo de $45 \mu \mathrm{m}$, e colocando no frigorífico.

\section{Ensaios em Culturas Batch}

A avaliação do crescimento da C. vulgaris, na presença dos extratos aquosos, foi feita em culturas batch. As culturas de C. vulgaris em fase exponencial foram transferidas para Erlenmeyer sde $250 \mathrm{~mL}$, previamente esterilizados, e expostas quer a diferentes concentrações de extratos (a frio e a quente), quer a diferentes tempos de extração, no caso dos extratos a frio, num total de 3 ensaios distintos, conforme figura 1. Todas as concentrações de extrato testadas foram realizadas em meio de Walne Modificado (v/v). Para cada ensaio foram realizadas culturas controlo, nas quais o volume de extrato foi substituído por água autoclavada. Os ensaios foram desenvolvidos em volumes de $200 \mathrm{~mL}$ e realizados em triplicado.

Os ensaios foram incubados em câmara de cultura à temperatura de $20^{\circ} \mathrm{C}$, intensidade luminosa de $4500 \mathrm{~lx}$ com fotoperíodo de $16 \mathrm{~h} / 8 \mathrm{~h}$ luz/escuro, sendo agitados manualmente uma vez por dia. A avaliação da densidade celular das culturas foi feita por contagem diária do número de células em câmara de Neubauer e os resultados expressos pelo incremento da densidade celular ocorrido durante a fase exponencial (Incremento) e taxa especifica de crescimento $(\mu)$. O teor de proteínas nas microalgas foi determinado pelo método de Bradford (Bradford, 1976). Resumidamente, após extração dos pigmentos foram adicionados $5 \mathrm{~mL}$ de $\mathrm{NaOH} / 0,5 \mathrm{M}$ às amostras. Estas foram incubadas em banhomaria durante $20 \mathrm{~min}$. Após o arrefecimento as amostras foram centrifugadas (3500 rpm/15 min), seguindo-se a leitura a $595 \mathrm{~nm}$ do sobrenadante (Nanocolor UV/VIS 60 $\mathrm{Hz}$ ). A concentração de proteínas totais foi feita considerando uma curva de calibração utilizando albumina de soro bovino como padrão e os resultados expressos em pg/célula. O teor em clorofila a foi determinado epectrofotometricamente (Jeffrey e Humphrey, 1975) e os resultados foram expressos em $\mu \mathrm{g} / \mathrm{mL}$. 
Figura 1 - Esquema representativo da metodologia usada nas culturas batch.

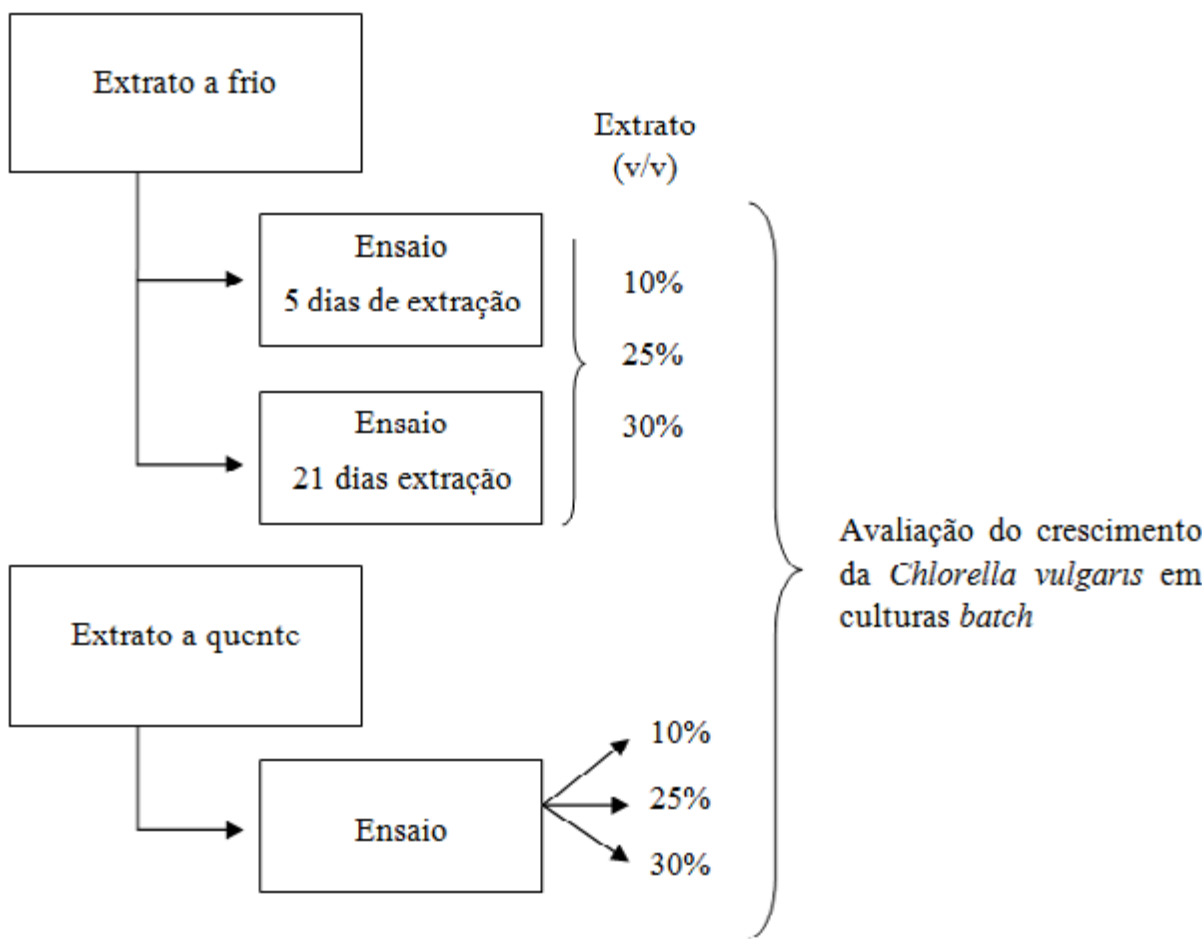

Identificação dos Compostos Fenólicos nos Extratos Aquosos

A identificação e quantificação dos compostos fenólicos presentes nos extratos foi feita por HPLC, em 2 tipos de extratos: extratos aquosos de alecrim a quente e extratos aquosos de alecrim a frio com 21 dias de extração. As amostras foram submetidas a uma hidrólise ácida com $\mathrm{HCl}$ e hidrólise com $\mathrm{MeOH}$, água e TBHQ (tert-butilhidroquinona, antioxidante), para eliminação dos açúcares. Resumidamente, para microtubos com tampa retiraram-se $200 \mu \mathrm{L}$ de cada extrato vegetal e procedeu-se à sua evaporação com azoto gasoso. Após a completa evaporação, adicionou-se $200 \mu \mathrm{L}$ de HLC a 2M em metanol a 50\% (água: metanol, v/v) e $200 \mu \mathrm{L}$ de uma solução de 50\% de metanol (água: metanol, v/v) eTBHQ. Os microtubos foram colocados em bloco de aquecimento a 80 ${ }^{\circ} \mathrm{C}$, durante $2 \mathrm{~h}$ e de seguida centrifugados. Após a centrifugação transferiu-se o sobrenadante para vials de HPLC, os quais foram mantidos a $-20^{\circ} \mathrm{C}$ até a sua análise.

Para a separação cromatográfica foi utilizada uma coluna de fase reversa do tipo C18, com enchimento Spherisorb ODS2 de $5 \mu \mathrm{L}$ (Phase Separations, WATERS). A fase móvel consistiu em água ultrapura com $1 \%$ (v/v) de ácido tricloroacético (TFA) (solvente A) e acetonitrilo com 1\% TFA (solvente B). A eluição foi realizada a um fluxo de solvente de $1 \mathrm{~mL} /$ minuto, com gradiente a começar com $100 \%$ de A, sendo o volume de injeção de $10 \mu \mathrm{l}$. As amostras foram analisadas num sistema HPLC com detetor UV (LCQ Advantage Max, ThermoFinnigan). Os cromatogramas foram registados a 280, 320, 370 e $520 \mathrm{~nm}$. A identificação dos compostos fenólicos individuais foi feita por comparação com padrões comerciais externos (Extrasynthese,
França), através dos respetivos tempos de retenção e espectros UV. A quantificação foi feita utilizando parâmetros como o volume de extração, volume de injeção, área do padrão interno, área do composto em questão. O LC-MS/MS foi utilizado para confirmar os resultados.

\section{Análise Estatística}

A análise estatística foi efetuada usando o software estatístico SPSS 19.0 e um nível de significância de 5\%. O teste de Shapiro-Wilk foi realizado para demonstrar a existência de normalidade dos parâmetros e o teste de Levene para testar a homogeneidade das variâncias. Foram comparados os valores da clorofila e proteína, usando Anova e o teste de Tukey para comparações múltiplas (Post-Hoc).

O teste de Mann-Whitney foi usado para identificar diferenças, para cada ensaio, nos valores médios da taxa específica de crescimento, do incremento celular e da concentração celular final, entre culturas incubadas com diferentes percentagens de extrato aquoso de alecrim. Utilizaram-se correlações de Spearman's para identificar relações entre a taxa específica de crescimento e as concentrações de extrato testadas. Os resultados foram expressos como valores médios \pm DP (Desvio Padrão da média).

\section{Resultados E Discussão}

Ensaios com extratos aquosos a frio

Os ensaios com os extratos aquosos de alecrim a frio foram realizados com 5 e 21 dias de extração, nas concentrações 
de $10 \%, 25 \%$ e $30 \%$ e decorreram durante 264 horas (11 dias). Os valores médios da taxa específica de crescimento e do incremento celular ocorrido na fase exponencial, encontrados para estas culturas encontram-se na tabela 1. Para os extratos com 5 dias de extração, os resultados mostram que a fase exponencial de crescimento, a grosso modo, teve igual duração. Nas culturas controlo o crescimento em média foi exponencial a partir das 72 horas ( $3^{\circ}$ dia) estendendo-se até às 192 horas
( $8^{\circ}$ dia). Comparativamente, as culturas incubadas na presença de $10 \%$ de extrato apresentaram uma fase exponencial entre as 48 horas ( $2^{\circ}$ dia) e as 192 horas ( $8^{\circ}$ dia), nas culturas suplementadas com $25 \%$ de extrato a fase exponencial iniciouse sensivelmente às 96 horas ( $4^{\circ}$ dia) e quando suplementadas com 30\% de extrato às 72 horas ( $3^{\circ}$ dia), estendendo-se em ambas até ás 216 horas ( $\left.9^{\circ} \mathrm{dia}\right)$, conforme tabela

Tabela 1 - Valores médios de taxa específica de crescimento ( $\mu$ ), duração da fase exponencial (Duração) e incremento celular ocorrido na fase exponencial (Incremento) para C. vulgaris incubada com diferentes concentrações de extrato aquoso de alecrim a frio, com 5 e 21 dias de extração. $\mathrm{N}=3$

\begin{tabular}{|c|c|c|c|c|c|}
\hline & & Controlo & $10 \%$ & $25 \%$ & $30 \%$ \\
\hline \multirow{3}{*}{$\begin{array}{c}5 \text { dias } \\
\text { extração }\end{array}$} & $\mu\left(\mathbf{h}^{-1}\right)$ & $0,012 \pm 0,001$ & $0,013 \pm 0,005$ & $0,007 \pm 0,004$ & $0,018 \pm 0,012$ \\
\hline & Duração (dias) & $3^{\circ}-8^{\circ}$ & $2^{\circ}-8^{\circ}$ & $4^{\circ}-9^{\circ}$ & $3^{\circ}-9^{\circ}$ \\
\hline & $\begin{array}{c}\text { Incremento } \\
\left(\mathrm{n}^{\circ} \text { células } \times 10 \mathrm{E} 5 / \mathrm{mL}\right)\end{array}$ & $145 \pm 21$ & $240 \pm 30$ & $219 \pm 120$ & $302 \pm 93$ \\
\hline \multirow{3}{*}{$\begin{array}{c}21 \text { dias } \\
\text { extração }\end{array}$} & $\mu\left(\mathbf{h}^{-1}\right)$ & $0,004 \pm 0,0006^{a}$ & $0,019 \pm 0,004^{\mathrm{b}}$ & $0,022 \pm 0,002^{\mathrm{b}}$ & $0,040 \pm 0,008^{c}$ \\
\hline & Duração (dias) & $2^{\circ}-11^{\circ}$ & $2^{\circ}-11^{\circ}$ & $3^{\circ}-11^{\circ}$ & $5^{\circ}-9^{\circ}$ \\
\hline & $\begin{array}{c}\text { Incremento } \\
\left(\mathrm{n}^{\circ} \text { células } \times 10 \mathrm{E} 5 / \mathrm{mL}\right)\end{array}$ & $10 \pm 2^{a}$ & $158 \pm 12^{\mathrm{b}}$ & $215 \pm 20^{b}$ & $132 \pm 14^{b}$ \\
\hline
\end{tabular}

Letras diferentes correspondem a diferenças estatisticamente diferentes, para o mesmo ensaio.

Além disso, a presença dos extratos aquosos de alecrim a frio com 5 dias de extração não influenciaram a taxa de crescimento, já que não se observaram diferenças significativas nos valores médios da $\boldsymbol{\mu}$. Também o incremento celular médio e a densidade celular final não apresentaram diferenças para a C. vulgaris quando incubada nas diferentes concentrações de extrato, comparativamente às culturas controlo.

Para os extratos com 21 dias de extração, mais uma vez, a fase exponencial de crescimento teve igual duração, exceto para as culturas incubadas com 30\% de extrato. Nas culturas controlo o crescimento em média foi exponencial a partir das 48 horas ( $2^{\circ}$ dia) estendendo-se até ao final do ensaio. De modo muito semelhante, as culturas suplementadas com 10\% e $25 \%$ de extrato de alecrim apresentaram crescimento exponencial a partir das 48 horas ( $2^{\circ}$ dia) e 72 horas ( $3^{\circ}$ dia), respetivamente, prolongando-se também até ao último dia. No entanto, as culturas suplementadas com $30 \%$ de extrato apresentaram crescimento exponencial durante um período mais curto, iniciando-se bastante mais tarde, por volta das 120 horas $\left(5^{\circ}\right.$ dia) e prolongando-se até às 216 horas ( $\left.9^{\circ} \mathrm{dia}\right)$, conforme tabela 1 , sugerindo necessidade de adaptação metabólica das células.

Por outro lado, a presença destes extratos com 21 dias de extração influenciaram a taxa de crescimento. De facto, observaram-se aumentos significativas nos valores médios da $\boldsymbol{\mu}$ e no incremento celular médio ocorrido na fase exponencial da C. vulgaris quando incubada com extratos, comparativamente ao controlo (Tabela 1). As culturas com diferentes concentrações de extratos foram iniciadas com uma concentração média de 2,83 $\pm 0,78$ células $\times 10 \mathrm{E} 5 / \mathrm{mL}$, enquanto as culturas controlo foram iniciadas com 5,95 $\pm 0,59$ células x $10 \mathrm{E} 5 / \mathrm{mL}$, apesar disso a densidade celular final foi manifestamente superior nas culturas com extratos, já que no mínimo foi 10 vezes superior à densidade celular final dos controlos (Figura 2). 
Figura 2 - Curvas de crescimento para C. vulgaris incubada com diferentes concentrações de extrato aquoso de alecrim a frio, com 21 dias de extração: A- Controlo; B- 10\% de extrato; C- 25\% de extrato; D- 30\% de extrato (EA, EB, EC = triplicados).
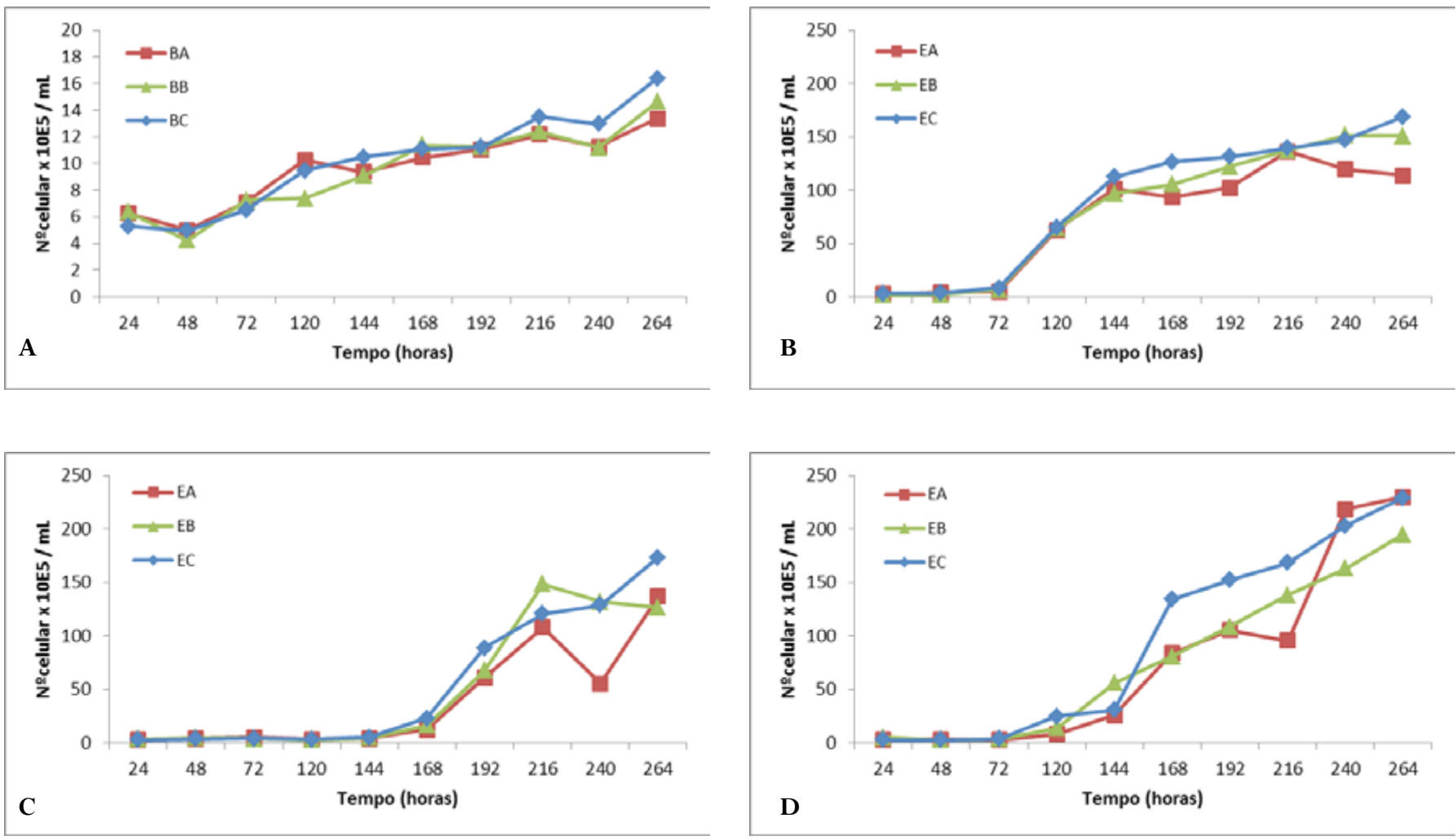

A variação dos teores de clorofila $a(\mathrm{Chl} a)$ para estes ensaios foi concordante com os resultados anteriores. De facto, a biomassa do fitoplâncton em termos de concentração de Chl a é um dos métodos mais amplamente aceite no estudo da produção biológica, como indicativo do material vegetal total disponível (Weyhenmeyer et al., 1999). Como seria de

esperar, o aumento em Chl a observado para todas as culturas, acompanhou a fase exponencial de crescimento. Além disso, para os extratos de 21 dias, aumentaram significativamente ao longo do tempo de cultura, comparativamente às culturas controlo (Figura 3).

Figura 3 - Variação da concentração da Chl a $(\mu \mathrm{g} / \mathrm{mL})$, para C. vulgaris: A- incubação com extrato aquoso de alecrim a frio com 5 dias de extração; B - incubação com extrato aquoso de alecrim a frio com 21 dias de extração (BB=controlo; E10=10\% extrato; E25=25\% extrato; $\mathrm{E} 30=30 \%$ extrato; $\mathrm{N}=3$ ).
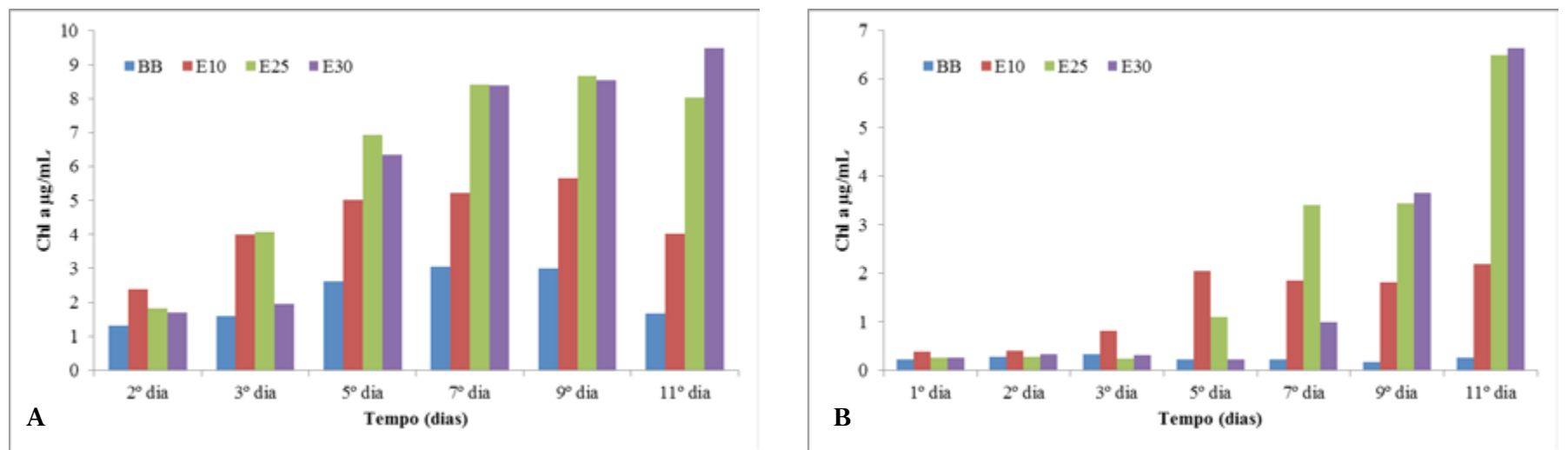
Assim, os resultados mostram que o extrato aquoso de alecrim a frio, com 5 dias de extração, não afeta o crescimento da C. vulgaris, por outro lado quando o tempo de extração se prolonga para 21 dias, ocorre estímulo do crescimento, nas condições de incubação testadas. Neste caso, verificaram-se aumentos quer da taxa de crescimento, quer no incremento celular médio ocorrido na fase exponencial e por isso também na densidade celular final e no teor em $\mathrm{Chl} a$. Comparativamente às culturas controlo, a $C$. vulgaris na presença de extrato com 21 dias, mostrou aumento significativo destes parâmetros, em função da concentração testada. De facto foi encontrada uma correlação positiva entre a concentração dos extratos aquosos a frio de alecrim, com 21 dias de extração, e a taxa específica média de crescimento da $C$.vulgaris $(\mathrm{n}=11, \mathrm{r}=0,923, \mathrm{p}<0,01)$. Estes resultados apontam para um estímulo do crescimento na presença do extrato a frio de alecrim, com 21 dias de extração e mostram uma relação de aumento da densidade celular com o aumento da concentração de extrato, nas gamas testadas, sugerindo a presença de maior concentração e/ou a existência de outros compostos, comparativamente aos extratos com 5 dias, que de alguma forma podem funcionar como suplemento nutricional. Apesar de vários compostos fenólicos tipicamente apresentarem atividade antialgal, incluindo inibição do crescimento (Stom and Roth, 1981; Aruoja et al, 2011; Shao et al., 2013), algumas espécies de microalgas conseguem degradar ou absorver compostos fenólicos quando as suas concentrações são mais baixas (Al-Khalid and El-Naas, 2012). Também Megharaj et al. (1992) observaram diminuição da toxicidade associada a compostos fenólicos e até estímulo do crescimento de C. vulgaris, em culturas sob condições fotoheterotróficas. Do mesmo modo, EI-Sheekh et.al. (2012) observaram degradação de alguns compostos fenólicos pela $C$. vulgaris, confirmando a capacidade que algumas algas apresentam de oxidar compostos fenólicos.

O doseamento das proteínas totais é geralmente usado como um parâmetro de avaliação da biomassa. Neste estudo, os resultados expressos por célula servem como um indicador da condição fisiológica da cultura, nomeadamente de atividade metabólica. Para a maior percentagem de extrato com 5 dias, ou seja $30 \%$, verificou-se um pico acentuado ao $3^{\circ}$ dia, coincidente com o início da fase exponencial (Figura 4 D), sugerindo um aumento da síntese de proteínas necessárias para a degradação dos compostos presentes no extrato de alecrim.

Figura 4 - Valores da proteína em pg/célula para C. vulgaris incubada com diferentes concentrações de extrato aquoso de alecrim a frio, com 5 dias de extração: A- Controlo; B- 10\% de extrato; C- 25\% de extrato; D- 30\% de extrato. N=3
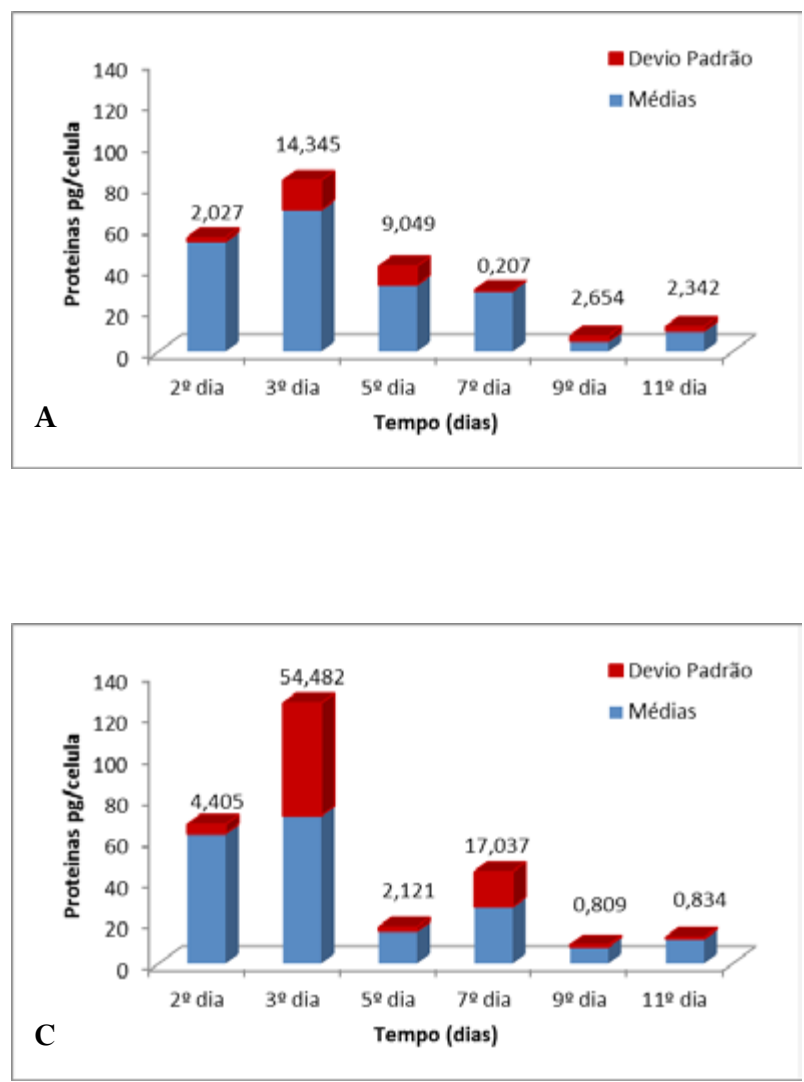
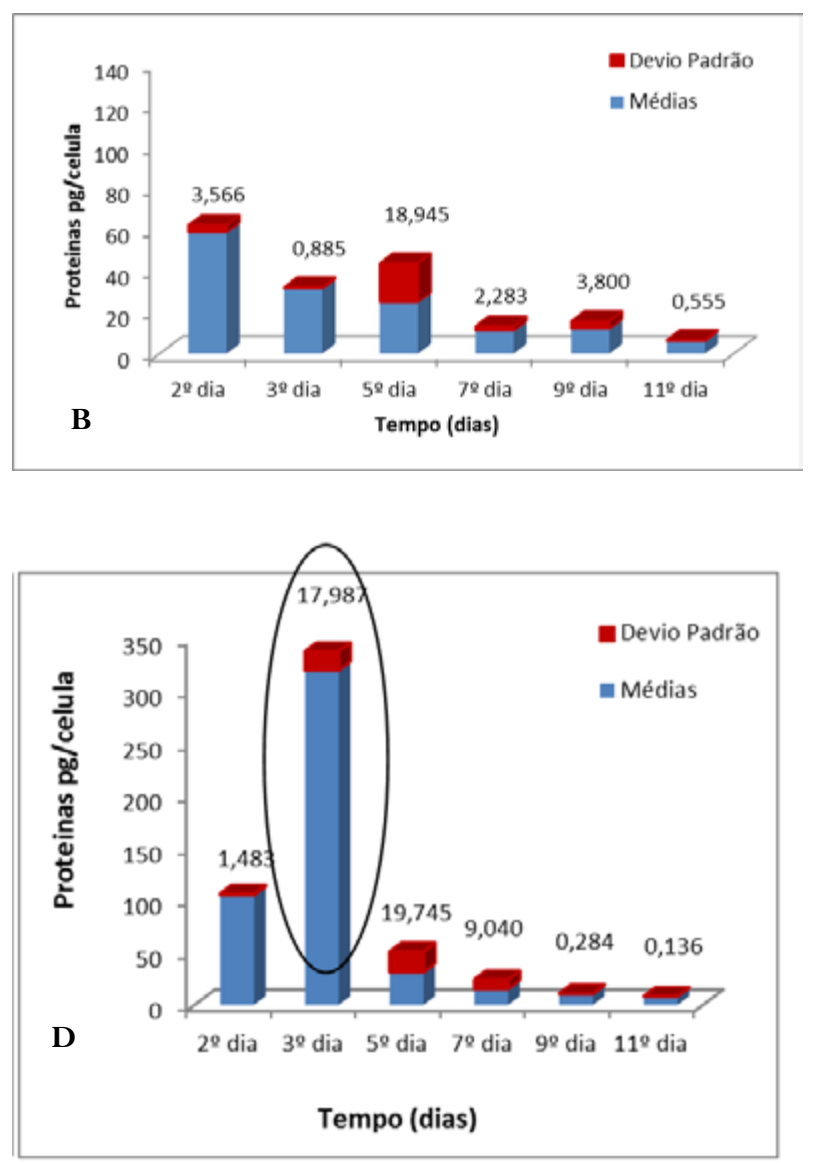
Mais uma vez os picos observados nas culturas expostas a 25\% e 30\% de extrato com 21 dias (Figura 5 C e D) poderão ser o resultado de uma resposta metabólica necessária para a degradação dos compostos presentes nestes extratos, já que se verificam durante a fase exponencial do crescimento.

Figura 5 - Valores da proteína em pg/célula para C. vulgaris incubada com diferentes concentrações de extrato aquoso de alecrim a frio, com 21 dias de extração: A- Controlo; B- 10\% de extrato; C- 25\% de extrato; D- 30\% de extrato. N=3
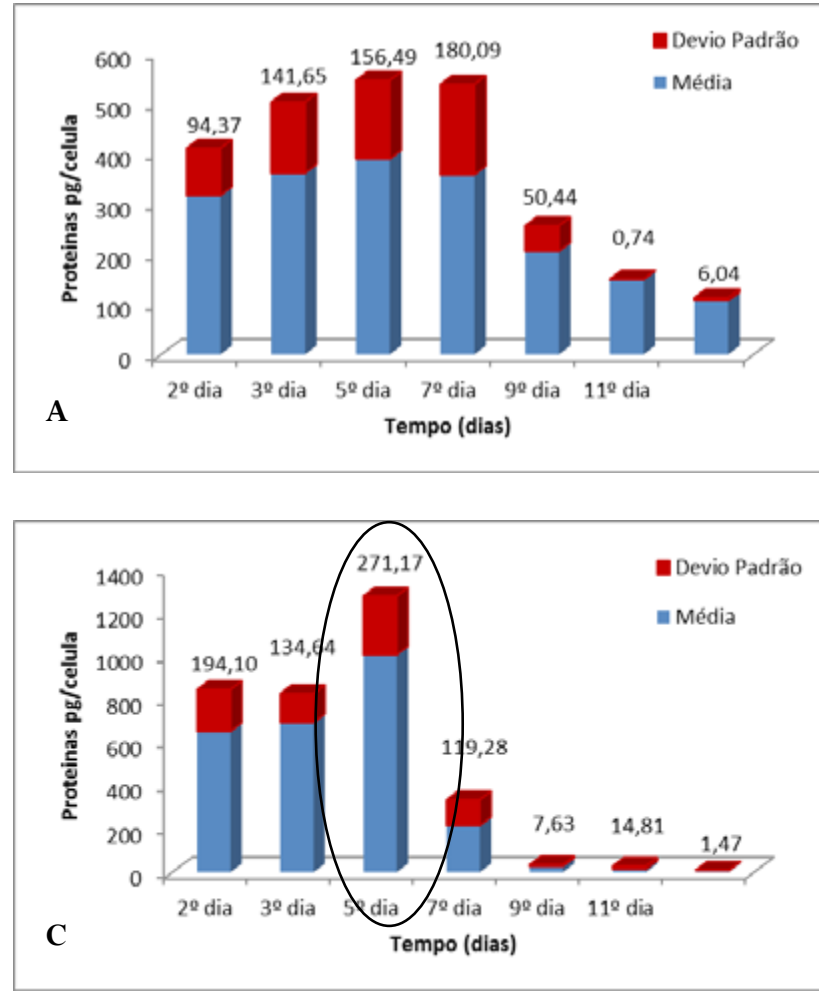

Ensaios com extratos aquosos a quente

Os ensaios com extratos de alecrim a quente foram avaliados durante um período total de 216 horas (9 dias). Para as culturas expostas aos extratos, embora a fase exponencial de crescimento se tenha iniciado ao mesmo tempo ( $2^{\circ}$ dia), a sua duração foi aumentando de forma proporcional à concentração de extrato testada. De facto, para as concentrações 10\%, 25\% e $30 \%$ de extrato, a fase exponencial prolongou-se até ao $5^{\circ}$ dia, $6^{\circ}$ dia e $8^{\circ}$ dia, respetivamente. Estes extratos também influenciaram a taxa de crescimento da $C$. vulgaris, já que na
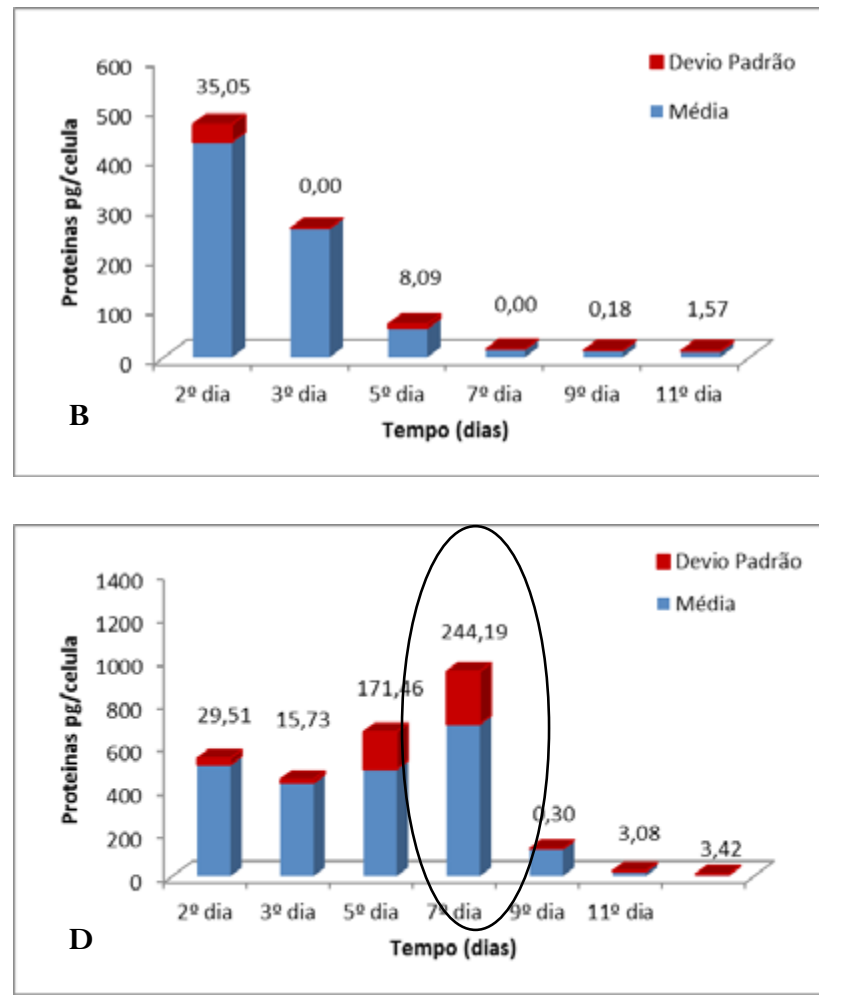

sua presença os valores médios da $\boldsymbol{\mu}$ foram superiores, comparativamente ao controlo, bem como o incremento celular médio ocorrido na fase exponencial (Tabela 2). Assim, não é de estranhar que a densidade celular final da $C$. vulgaris, quando incubada com extratos, fosse superior ao controlo, nomeadamente $3 \mathrm{x}, 4 \mathrm{x}$ e $5 \mathrm{x}$ maior densidade celular final, de forma mais uma vez proporcional à concentração de extrato testada. Apesar disso, não foi encontrada nenhuma relação entre a concentração dos extratos aquosos a quente de alecrim e a taxa específica média de crescimento da C. vulgaris.

Tabela 2 - Valores médios de taxa específica de crescimento $(\mu)$, duração da fase exponencial (Duração) e incremento celular ocorrido na fase exponencial (Incremento) para C. vulgaris incubada com diferentes concentrações de extrato aquoso de alecrim a quente. $\mathrm{N}=3$

\begin{tabular}{|c|c|c|c|c|}
\hline & Controlo & $10 \%$ & $25 \% *$ & $30 \%$ \\
\hline $\begin{array}{c}\mu \\
\left(\mathbf{h}^{-1}\right)\end{array}$ & $0,005 \pm 0,0009^{a}$ & $0,017 \pm 0,0007^{b}$ & $0,016 \pm 0,0002^{b}$ & $0,011 \pm 0,0019^{b}$ \\
\hline $\begin{array}{c}\text { Duração } \\
\text { (dias) }\end{array}$ & $5^{\circ}-8^{\circ}$ & $2^{\circ}-5^{\circ}$ & $2^{\circ}-6^{\circ}$ & $2^{\circ}-8^{\circ}$ \\
\hline $\begin{array}{c}\text { Incremento } \\
\left(\mathrm{n}^{\circ} \text { células } \times 10 \mathrm{E} 5 / \mathrm{mL}\right)\end{array}$ & $14 \pm 4^{a}$ & $62 \pm 6^{b}$ & $142 \pm 13^{c}$ & $150 \pm 22^{c}$ \\
\hline
\end{tabular}

$\mathrm{N}=2$; Letras diferentes correspondem a diferenças estatisticamente diferentes. 
Os valores obtidos da concentração da Chl a para estes ensaios, mostram para o controlo, que o aumento acompanhou a fase exponencial de crescimento. No entanto as culturas com $25 \%$ e $30 \%$ de extrato a quente têm um decréscimo da Chl $a$, a partir do $3^{\circ}$ dia e para as culturas com $10 \%$ de extrato, a partir do $5^{\circ}$ dia (Figura 6). Estes resultados parecem inesperados já que se esperava que a evolução pigmentar acompanhasse o crescimento da biomassa. Esta situação pode advir de alterações metabólicas resultantes, quer da presença de novos compostos, quer do aumento da concentração de compostos, comparativamente ao extrato a frio de alecrim que deprimem a concentração da clorofila, mas que apesar disso não inibem o crescimento da biomassa. O facto de os compostos fenólicos serem inibidores da atividade fotossintética, levando à diminuição da clorofila a (Megharaj et al., 1992; HerreraSilveira and Ramfrez-Ramfrez, 1996), suporta esta observação.

Figura 6 - Variação da concentração da $\mathrm{Chl}$ a $(\mu \mathrm{g} / \mathrm{mL})$, para $C$. vulgaris incubada com diferentes concentrações aquosas de alecrim a quente. $(\mathrm{BB}=$ controlo; $\mathrm{E} 10=10 \%$ extrato; $\mathrm{E} 25=25 \%$ extrato; $\mathrm{E} 30=30 \%$ extrato $\mathrm{N}=3)$

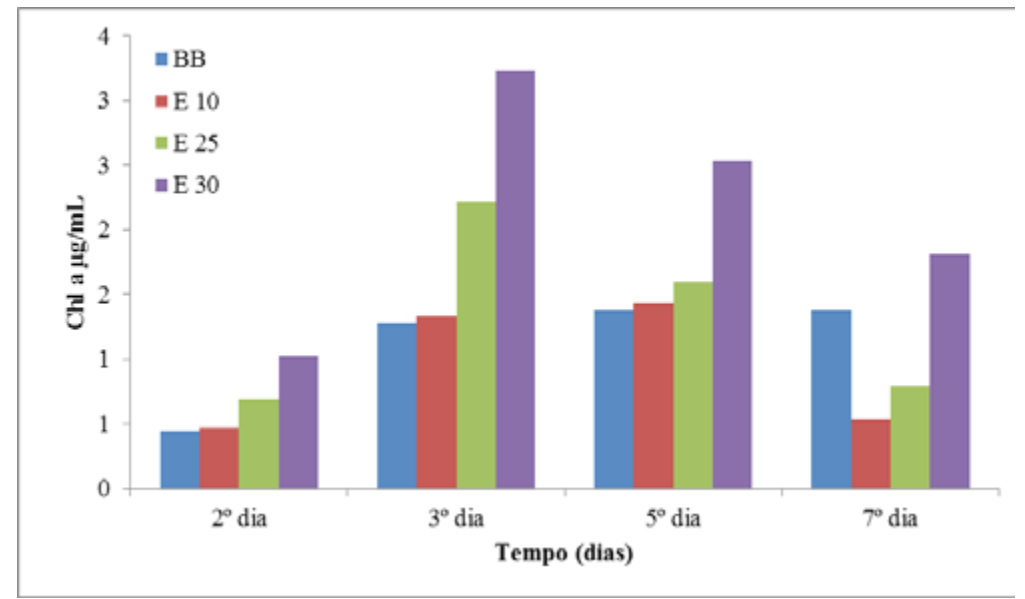

Também se verifica de um modo geral, que os valores de proteína por célula, nas culturas com extrato a quente, são inferiores aos valores do controlo. Além disso, para as culturas com 30\% de extrato, os valores da proteína por célula diminuem com o tempo de cultura, contrariamente ao observado para $10 \%$ e $25 \%$ de extrato (Figura 7). A eventual inibição da síntese de clorofila observada poderá estar relacionada com esta diminuição do teor de proteína. Segundo Megharaj et al. (1992), os compostos fenólicos exercem efeitos tóxicos que se manifestam, para além da diminuição do teor de clorofila, também na diminuição do teor de proteínas.

Figura 7 - Valores da proteína em pg/célula para C. vulgaris incubada com diferentes concentrações de extrato de alecrim a quente: A- Controlo; B- $10 \%$ de extrato; C- 25\% de extrato; D- 30\% de extrato. $N=3$.

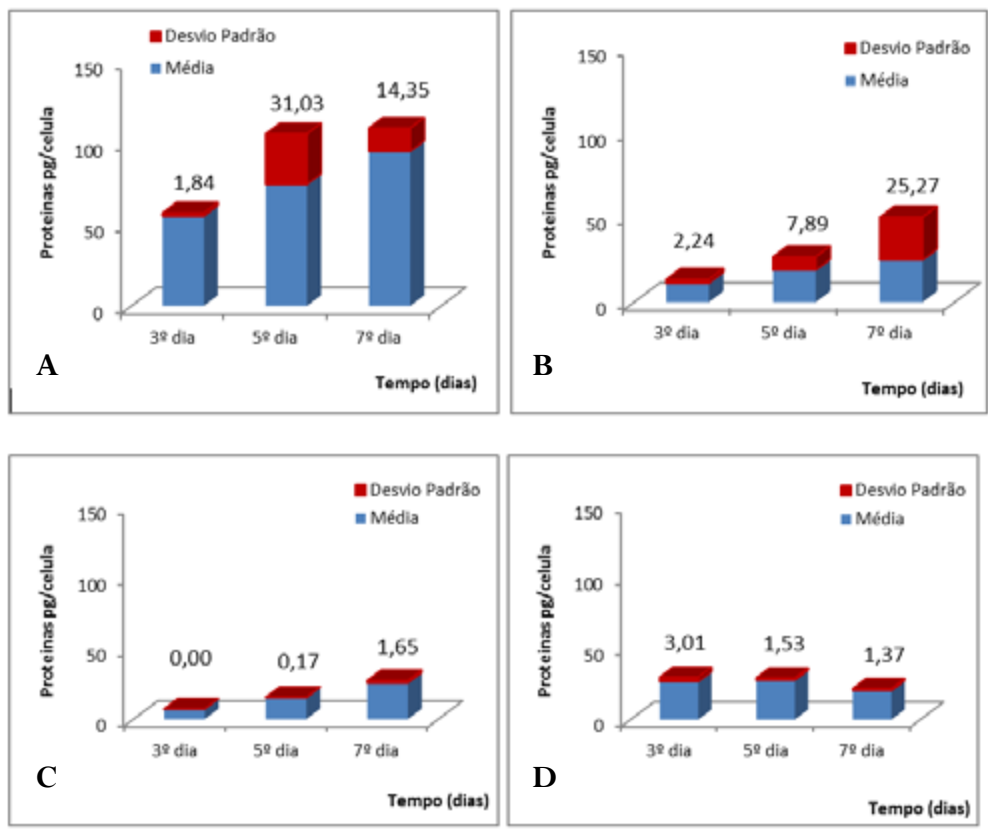


Compostos Fenólicos nos Extratos Aquosos

No extrato de alecrim obtido a frio com 21 dias, foi detetado e quantificado o ácido rosmarínico e a quercetina (Tabela 3). Os resultados obtidos com C. vulgaris apontam para um estímulo do crescimento na presença deste extrato e mostram uma relação direta com o aumento da concentração de extrato, nas gamas testadas. $\mathrm{O}$ ácido rosmarínico tem atividade antiviral, antibacteriana, anti-inflamatório e antioxidante (Petersen and Simmonds, 2003; Pietsch et al., 2011). À quercetina são também atribuídas propriedades antiviral, antiinflamatória e antioxidante, e além destas também analgésica, antialérgica e bactericida (Lakhanpal et al., 2007; Pietsch et al., 2011). No entanto, apesar do ácido rosmarinico e da quercitina apresentarem ação antibacteriana podem estar, nas concentrações testadas, abaixo da concentração inibitória. Por outro lado, as vias metabólicas na manifestação dos efeitos tóxicos são seguramente diferentes, já que a $C$. vulgaris é eucariota.

Tabela 3 - Quantificação dos compostos fenólicos identificados nos dois tipos de extrato de alecrim analisados.

\begin{tabular}{|c|c|c|}
\hline Composto fenólico & Amostra & $\begin{array}{c}\text { Total } \\
(\mu \mathrm{g} / \mathrm{g} \text { peso seco }) *\end{array}$ \\
\hline \multirow{2}{*}{ Ácido gálico } & Extrato a frio & n.d. \\
\hline & Extrato a quente & 14,00 \\
\hline \multirow{2}{*}{ Ácido clorogénico } & Extrato a frio & n.d. \\
\hline & Extrato a quente & 1,43 \\
\hline \multirow{2}{*}{ Ácido cafeico } & Extrato a frio & n.d. \\
\hline & Extrato a quente & 4,09 \\
\hline \multirow{2}{*}{ Luteolina-7-O-glucoside } & Extrato a frio & n.d. \\
\hline & Extrato a quente & 5,40 \\
\hline \multirow{2}{*}{ Luteolina-4-O-glucoside } & Extrato a frio & n.d. \\
\hline & Extrato a quente & 4,09 \\
\hline \multirow{2}{*}{ Quercetina-3-O-rhamnoside } & Extrato a frio & 76,70 \\
\hline & Extrato a quente & 3,54 \\
\hline \multirow{2}{*}{ Ácido rosmarínico } & Extrato a frio & 1116,85 \\
\hline & Extrato a quente & 44,18 \\
\hline
\end{tabular}

* Média de três repetições; Erro padrão da média $= \pm 0,1 ;$ n.d. $=$ não detetado

As microalgas são sensíveis aos compostos fenólicos, no entanto o seu efeito tóxico irá depender do número e polaridade dos anéis aromáticos presentes (Pinto et al., 2002), bem como seguramente da sua concentração, tempo de exposição e provavelmente das condições de cultura. É de notar que os efeitos tóxicos de compostos fenólicos são revertidos e/ou atenuados na C. vulgaris, em situação fotoheterotrófica (Megharaj et al., 1992). Por outro lado, Luna et al. (1996) demonstraram que a quercetina induz um aumento do crescimento celular, diminuindo a peroxidação de lípidos ao nível da membrana.

Verificou-se que existem diferenças na composição química entre os extratos a frio e a quente. Na figura 8 é apresentado a título de exemplo, o perfil cromatográfico do extrato de alecrim obtido a quente, onde se podem visualizar os espectros dos picos com maior intensidade e seus respetivos tempos de retenção. Esta diferença entre os extratos a quente e extratos a frio deve estar ligada à maior capacidade extrativa do solvente (água) a temperatura elevada. Comparativamente ao extrato a frio, o extrato a quente apresenta mais variedade de compostos fenólicos, já que foram identificados e quantificados 7 compostos distintos, tendo sido detetado maioritariamente o ácido rosmarínico e o ácido gálico (Tabela 3). O ácido rosmarínico aparece neste extrato em muito menor concentração, comparativamente ao extrato a frio, o que sugere que a temperatura terá efeito negativo na estabilidade deste composto.

$\mathrm{O}$ ácido gálico apresenta atividade antibacteriana, antiviral, bem como atividade analgésica e anti-apoptótica (Belur, 2011). Apesar disso, o facto dos extratos aquosos de alecrim a quente aumentarem a taxa de crescimento da C. vulgaris, aparentemente dependente da concentração 
testada, poderá ser devido às baixas concentrações testadas que não serão suficientes para manifestar o potencial efeito algistático e/ou algicida. Por outro lado, a presença de mais variedade de compostos poderá ter funcionado como substratos suplementares. Nestas condições, C. vulgaris, parece ter capacidade para metabolizar os compostos fenólicos, utilizando-os como fonte de carbono, apesar de ser visivel alguma toxicidade a nível fisiológico (pigmentos e proteínas). Estes resultados são confirmados pelo facto do grau de inibição/estímulo do crescimento de microalgas mostrar relação com a concentração de compostos fenólicos, já que na presença de baixas concentrações se verifica um efeito positivo no crescimento (Megharaj et al., 1992; Herrera-Silveira and Ramfrez-Ramfrez, 1996; EI-Sheekh, et al., 2012).

Figura 8 - Perfil dos fenólicos individuais detetados por HPLC em extratos de alecrim a quente.
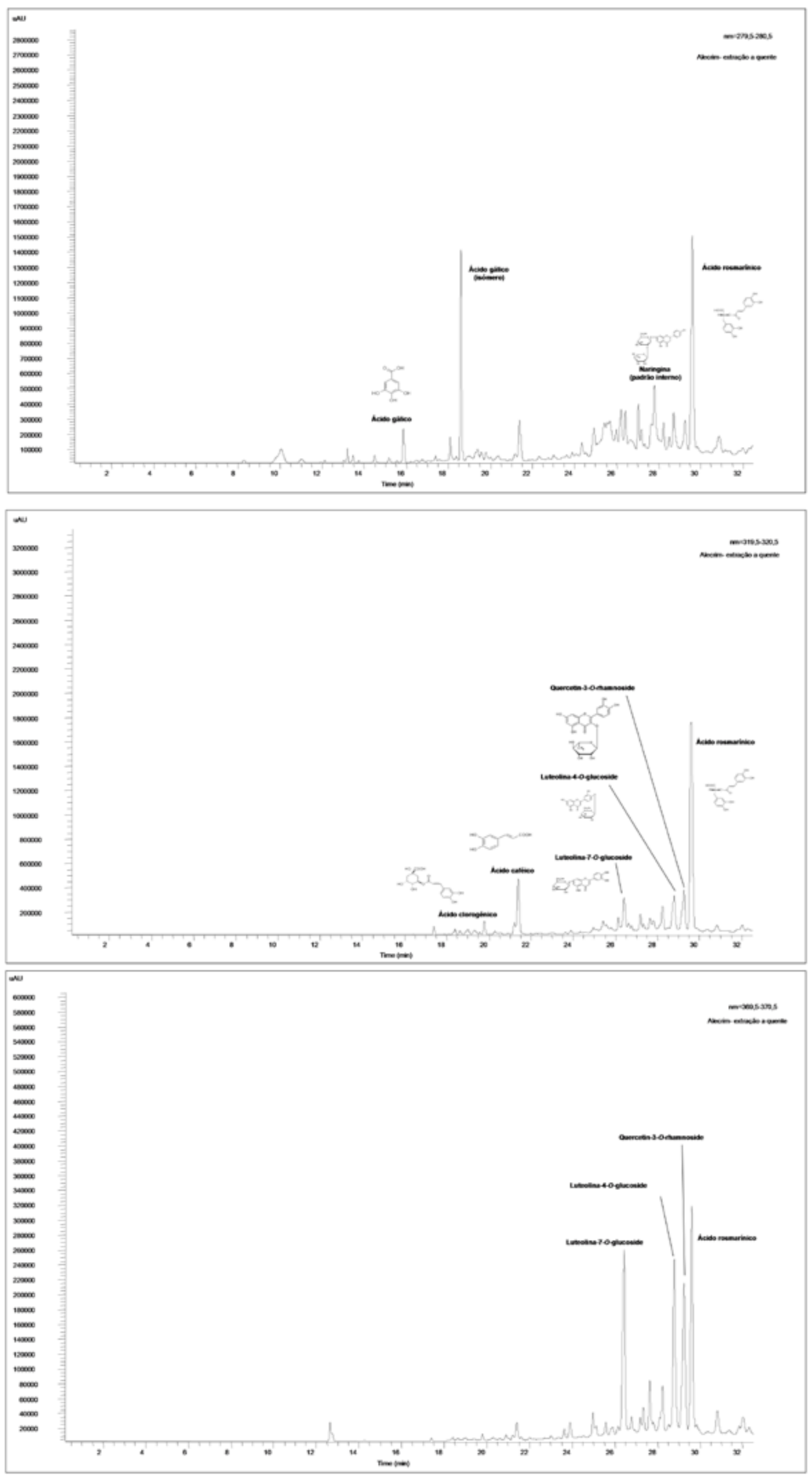


\section{Conclusões}

Os resultados obtidos neste trabalho, nomeadamente o estímulo do crescimento de $C$. vulgaris na presença do diferentes compostos fenólicos, confirmam que as microalgas apresentam capacidade para os degradar. No entanto os mecanismos de toxicidade, associados ao aumento da concentração de compostos fenólicos, manifestam-se, entre outros, no metabolismo proteico e pigmentar. Os extratos a frio com 5 dias de extração não afetam o crescimento da Chlorella vulgaris, provavelmente porque a concentração de compostos fenólicos é muito baixa. Por outro lado quando o tempo de extração se prolonga para 21 dias, ocorre estímulo do crescimento e do teor em Chl $a$, em função da concentração testada. Os picos no teor da proteína observados nestas culturas expostas á maior concentração de extrato poderão ser o resultado do aumento da síntese de proteínas necessárias para a degradação destes substratos. Para o extrato aquoso de alecrim a quente, os resultados permitem concluir que induzem aumento da taxa de crescimento, levando ao aumento do incremento celular médio ocorrido na fase exponencial e da densidade celular final da C. vulgaris. Apesar disso, nestas culturas observou-se uma diminuição acentuada da Chl a por célula e do teor de proteína, sugerindo alguns efeitos tóxicos de compostos fenólicos presentes nestes extratos. Estes efeitos tóxicos poderão advir do maior número de compostos fenólicos identificados e/ou dos seus efeitos sinérgicos, já que no extrato a frio só foram identificados 2 dos 7 compostos fenólicos.

Os resultados desta investigação são pertinentes sob dois pontos de vista: (1) os compostos fenólicos naturais com efeito inibidor no crescimento das microalgas poderão ser utilizados no desenvolvimento de tecnologias "amigas do ambiente" no controlo de populações de microalgas, em substituição de algicidas convencionais, estes últimos geralmente tóxicos persistentes para o ambiente; (2) as microalgas poderão ser utilizadas no tratamento de efluentes, na biorremoção de compostos fenólicos, constituindo uma alternativa a outras tecnologias actualmente existentes.

\section{REFERÊNCIAS}

Al-Khalid T and El-Naas M. 2012. Aerobic biodegradation of phenols: a comprehensive review. Critical Reviews in Environmenatal Science and Techology, 42: 1631-1690.

Aruoja V Sihtmäe M Dubourguier HC and Kahru A. 2011. Toxicity of 58 substituted anilines and phenols to algae Pseudokirchneriella subcapitata and bacteria Vibrio fischeri: comparison with published data and QSARs. Chemosphere, 84(10):1310-1320.

Belur PD and Pallabhanvi B. 2011. Investigation on production of gallic acid from Terminalia chebula extract using cell-associated tannase of Bacillus massiliensi. In International Conference on Advances in Biotechnology and Pharmaceutical Sciences (ICABPS'2011), p. 222-225.
Boulogne I Petit P Ozier-Lafontaine H Desfontaines L and Loranger-Merciris G. 2012. Insecticidal and antifungal chemicals produced by plants: a review. Environmental Chemistry Letters, 10:. 325-347.

Bradford MM. 1976. A Rapid and Sensitive Method for the Quantitation of Microgram Quantities of Protein Utilizing the Principle of Protein-Dye Binding. Analytical Biochemistry, 72: $248-254$.

EI-Sheekh MM Ghareib MM and EL-Souod GWA. 2012. Biodegradation of Phenolic and Polycyclic Aromatic Compounds by Some Algae and Cyanobacteria. J Bioremed Biodegrad., 3:133.

Fernandes C Barros S Galhano V and Geraldes AM. 2014. Searching for Algaecide or Algaestatic Effects of Several Plant Extracts on Phytoplankton: Preliminary Results. British Biotechnology Journal, 4: 1077-1087

Hafidh RR Abdulamir AS Vern LS Bakar F Abas F Jahanshiri F and Sekawi Z. 2011. Inhibition of Growth of Highly Resistant Bacterial and Fungal Pathogens by a Natural Product. Open Microbiol J., 5:96-106.

Herrera-Silveira JÁ and Ramfrez-Ramfrez J. 1996. Effects of natural phenolic material (tannin) on phytoplankton growth. Limnol. Oceanogr., 41(5): 1018-1023.

Jeffrey SW and Humphrey GF. 1975. New spectrophotometric equations for determining chlorophylls a, b, c1, and c2 in higher plants, algae and natural phytoplankton. Biochem. Physiol. Pflanzn. (BPP), 167: 191-194.

Lakhanpal P and Rai DK. 2007. Quercetin: A Versatile Flavonoid. Internet Journal of Medical Update, 2: 2237.

Laue P Bährs H Chakrabarti S and Steinberg CEW. 2014. Natural xenobiotics to prevent cyanobacterial and algal growth in freshwater: Contrasting efficacy of tannic acid, gallic acid, and gramine. Chemosphere 104:212-220.

Lika K and Papadakis IA. 2009. Modeling the biodegradation of phenolic compounds by microalgae. Journal of Sea Research 62: 135-146

Luna D Rodrigues OM Rada M and Mendez J. 1996. Actividad biológica de flavonoides. In Analis do $4^{\circ}$ Simpósio Internacional de Química de Productos Naturales y sus Aplicaciones. p. 134-135

Megharaj M Pearson HW and Venkateswarlu K. 1992. Effects of phenolic compounds on growth and metabolic activities of Chlorella vulgaris and Scenedesmus bijugatus isolated from soil. Plant and soil. 140: 25-34.

Miazek K Remacle C, Richel A and Goffin D. 2014. Effect of Lignocellulose Related Compounds on Microalgae Growth and Product Biosynthesis: A Review. Energies 7: 4446-4481.

Michałowicz J and Duda W. 2007. Phenols - Sources and Toxicity. Polish J. of Environ. Stud. 16:347-362 
Nakai S InoueY and Hosomi M. 2001. Algal growth inhibition effects and inducement modes by plant-producing phenols. Water Research, 35: 1855-1859

Petersen M and Simmonds MSJ. 2003. Molecules of interest: Rosmarinic acid. Phytochemistry, 62: 121-125.

Pietsch K Saul N Chakrabarti S Stürzenbaum SR Menzel $\mathrm{R}$ and Steinberg CEW. 2011. Hormetins, antioxidants and prooxidants: defining quercetin-, caffeic acid- and rosmarinic acid-mediated life extension in C.elegans. Biogerontology, 12: 329-347.

Pinto G Pollio A Previtera L andTemussi F. 2002. Biodegradation of phenols by microalgae. Biotechnology Letters, 24: 2047 2051.

Rauha JP Remes S Heinonen M Hopia A Kähkönen M Kujal T Pihlaja K Vuorela H and Vuorela P. 2000. Antimicrobial effects of Finnish plant extracts containing flavonoids and other phenolic compoundsInternational. Journal of Food Microbiology 56:3-12.
Shao J Li R Leo JE and Gu JD. 2013. Potential for control of harmful cyanocateriae blooms using biologically derived substances: problems and prospects. Journal of Environmental Management, 125: 149-155.

Stom DI and Roth R. 1981. Some effects of polyphenols on aquatic plants: I. Toxicity of phenols in aquatic plants. Bull. Envinm. Contam. Toxicol., 27: 332-337.

Weyhenmeyer G A Blenckner T and Pettersson K. 1999. Changes of the plankton spring outburst related to the North Atlantic Oscillation. Limnol Oceanogr, 47: 1788-1792.

Whiting DA. 2001. Natural phenolic compounds 1900-2000: a bird's eye view of a century's chemistry. Nat. Prod. Rep., 18: 583-606.

Zabka M and Pavela P. 2003. Antifungal efficacy of some natural phenolic compounds against significant pathogenic and toxinogenic filamentous fungi. Chemosphere, 93: 10511056. 